\title{
Neutral Rull-Based Emitting Materials: A Prototypical Study on Factors Governing Radiationless Transition in Phosphorescent Metal Complexes $^{\dagger}$
}

\author{
Elise Y. Li, Yi-Ming Cheng, Cheng-Chih Hsu, Pi-Tai Chou, ${ }^{*}$ and Gene-Hsiang Lee \\ Department of Chemistry and Instrumentation Center, National Taiwan University, \\ Taipei 106, Taiwan
}

I-Hui Lin and Yun Chi*

Department of Chemistry, National Tsing Hua University, Hsinchu 300, Taiwan

Chao-Shiuan Liu

Department of Chemistry, SooChow University, Taipei 111, Taiwan

Received January 13, 2006

\begin{abstract}
In addition to the metal-centered dd transition that is widely accepted as a dominant radiationless decay channel, other factors may also play important roles in governing the loss of phosphorescence efficiency for heavy-transitionmetal complexes. To conduct our investigation, we synthesized two dicarbonylruthenium complexes with formulas $\left[\mathrm{Ru}(\mathrm{CO})_{2}(\mathrm{BQ})_{2}\right](\mathbf{1})$ and $\left[\mathrm{Ru}(\mathrm{CO})_{2}(\mathrm{DBQ})_{2}\right](2)$, for which the cyclometalated ligands $\mathrm{BQ}$ and $\mathrm{DBQ}$ denote benzo$[h] q u i n o l i n e$ and dibenzo[f,h]quinoxaline, respectively. Replacing one $\mathrm{CO}$ ligand with a $\mathrm{P}$ donor ligand such as $\mathrm{PPh}_{2} \mathrm{Me}$ and $\mathrm{PPhMe}_{2}$ caused one cyclometalated ligand to undergo a $180^{\circ}$ rotation around the central metal atom, giving highly luminous metal complexes $\left[\mathrm{Ru}(\mathrm{CO}) \mathrm{L}(\mathrm{BQ})_{2}\right]$ and $\left[\mathrm{Ru}(\mathrm{CO}) \mathrm{L}(\mathrm{DBQ})_{2}\right]$, where $\mathrm{L}=\mathrm{PPh}_{2} \mathrm{Me}$ and $\mathrm{PPhMe} \mathrm{e}_{2}$ (3-6), with emission peaks $\lambda_{\max }$ in the range of $571-656 \mathrm{~nm}$ measured in the fluid state at room temperature. It is notable that the $S_{0}-T_{1}$ energy gap for both $\mathbf{1}$ and $\mathbf{2}$ is much higher than that of 3-6, but the corresponding phosphorescent spectral intensity is much weaker. Using these cyclometalated Ru metal complexes as a prototype, our experimental results and theoretical analysis draw attention to the fact that, for complexes $\mathbf{1}$ and $\mathbf{2}$, the weaker spin-orbit coupling present within these molecules reduces the $T_{1}-S_{0}$ interaction, from which the thermally activated radiationless deactivation may take place. This, in combination with the much smaller ${ }^{3} \mathrm{MLCT}$ contribution than that observed in 3-6, rationalizes the lack of room-temperature emission for complexes 1 and 2.
\end{abstract}

\section{Introduction}

One of the important research subjects toward organic light emitting diodes (OLEDs) is the development of phosphorescent materials that emit all three primary colors for fullcolor displays. This approach leads to the essentiality of preparing phosphors incorporating second- and third-row transition-metal complexes. ${ }^{1}$ The associated strong spinorbit coupling in heavy metals would promote singlet-totriplet intersystem crossing as well as enhance the subsequent radiative transition from the triplet to the ground state, giving

\footnotetext{
$\doteqdot$ Dedicated to Prof. John R. Shapley on the occasion of his 60th birthday. * To whom correspondence should be addressed. E-mail: chop@ntu.edu.tw (P.-T.C.), ychi@mx.nthu.edu.tw (Y.C.).
}

good phosphorescence efficiency for these metal complexes. Among the phosphorescent complexes, green-emitting complexes $^{2}$ have been known for years and were fabricated as OLED components with $\sim 100 \%$ internal quantum efficiency, while the red-emitting complexes are also accessible through judicious choices of chelate chromophores to lower the energy gap and extend the triplet-state lifetime ${ }^{3}$ as well as

(1) (a) Holder, E.; Langeveld, B. M. W.; Schubert, U. S. Adv. Mater. 2005, 17, 1109. (b) Hwang, F.-M.; Chen, H.-Y.; Chen, P.-S.; Liu, C.-S.; Chi, Y.; Shu, C.-F.; Wu, F.-I.; Chou, P.-T.; Peng, S.-M.; Lee, G.-H. Inorg. Chem. 2005, 44, 1344. (c) Tung, Y.-L.; Lee, S.-W.; Chi, Y.; Chen, L.-S.; Shu, C.-F.; Wu, F.-I.; Carty, A. J.; Chou, P.-T.; Peng, S.-M.; Lee, G.-H. Adv. Mater. 2005, 17, 1059. (d) Chou, P.-T.; Chi, Y. Eur. J. Inorg. Chem. 2006, 3319 (DOI 10.1002/ejic.200600364).

Inorganic Chemistry, Vol. 45, No. 20, 20068041 
to circumvent their intrinsic obstacle, namely, the rapid nonradiative deactivation predicted by the energy gap law. ${ }^{4}$

Presently, researchers have turned their attention to the preparation of the remaining blue-emitting phosphorescent complexes. ${ }^{5}$ This task, however, is even more difficult to achieve than those of the other two cases. One major challenge lies in the selection of suitable chelate ligands that are able to form complexes with sufficiently large ligandcentered $\pi \pi^{*}$ transition energies and/or metal-to-ligand charge-transfer (MLCT) energies. Such an approach might inevitably raise the ligand-centered transition (or MLCT) to a region very close to or even higher than the metal-centered dd states (or ligand-field, LF, states), such that a very efficient radiationless decay pathway may take place through a shallow potential energy surface or a possible $T_{1}-S_{0}$ intersection due to the weakness of the metal-ligand bonds.

To circumvent this obstacle, a few attempts have been made through the use of strong field ancillary ligands such as $\mathrm{CO}$ or cyanide with an aim to increase the dd transition. ${ }^{6}$ This, in combination with the incorporation of third-row metal elements, further strengthens the metal-ligand bonding. ${ }^{7}$ More recently, a series of blue-emitting pyridyl azolate osmium carbonyl complexes ${ }^{8}$ as well as iridium complexes with 2,4-difluorophenylpyridyl, pyrazolyl, and even $\mathrm{N}$ heterocyclic carbene ligands have been reported. ${ }^{9}$ These exquisite works demonstrate the feasibility of achieving a

(2) (a) Hua, F.; Kinayyigit, S.; Cable, J. R.; Castellano, F. N. Inorg. Chem. 2005, 44, 471. (b) Huang, W.-S.; Lin, J. T.; Chien, C.-H.; Tao, Y.-T.; Sun, S.-S.; Wen, Y.-S. Chem. Mater. 2004, 16, 2480. (c) Tokito, S.; Iijima, T.; Tsuzuki, T.; Sato, F. Appl. Phys. Lett. 2003, 83, 2459. (d) Lo, S.-C.; Namdas, E. B.; Burn, P. L.; Samuel, I. D. W. Macromolecules 2003, 36, 9721. (e) Adachi, C.; Baldo, M. A.; Forrest, S. R.; Thompson, M. E. Appl. Phys. Lett. 2000, 77, 904.

(3) (a) Tung, Y.-L.; Lee, S.-W.; Chi, Y.; Tao, Y.-T.; Chien, C.-H.; Cheng, Y.-M.; Chou, P.-T.; Peng, S.-M.; Liu, C.-S. J. Mater. Chem. 2005, 15, 460. (b) Anthopoulos, T. D.; Frampton, M. J.; Namdas, E. B.; Burn, P. L.; Samuel, I. D. W. Adv. Mater. 2004, 16, 557. (c) Tsuboyama, A.; Iwawaki, H.; Furugori, M.; Mukaide, T.; Kamatani, J.; Igawa, S.; Moriyama, T.; Miura, S.; Takiguchi, T.; Okada, S.; Hoshino, M.; Ueno, K. J. Am. Chem. Soc. 2003, 125, 12971. (d) Adachi, C.; Baldo, M. A.; Forrest, S. R.; Lamansky, S.; Thompson, M. E.; Kwong, R. C. Appl. Phys. Lett. 2001, 78, 1622.

(4) (a) Kober, E. M.; Caspar, J. V.; Lumpkin, R. S.; Meyer, T. J. J. Phys. Chem. 1986, 90, 3722. (b) Perkins, T. A.; Pourreau, D. B.; Netzel, T. L.; Schanze, K. S. J. Phys. Chem. 1989, 93, 4511.

(5) (a) Yeh, S.-J.; Wu, M.-F.; Chen, C.-T.; Song, Y.-H.; Chi, Y.; Ho, M.-H.; Hsu, S.-F.; Chen, C.-H. Adv. Mater. 2005, 17, 285. (b) Ren, X.; Li, J.; Holmes, R. J.; Djurovich, P. I.; Forrest, S. R.; Thompson, M. E. Chem. Mater. 2004, 16, 4743. (c) Karatsu, T.; Nakamura, T.; Yagai, S.; Kitamura, A.; Yamaguchi, K.; Matsushima, Y.; Iwata, T.; Hori, Y.; Hagiwara, T. Chem. Lett. 2003, 32, 886. (d) Holmes, R. J.; D’Andrade, B. W.; Forrest, S. R.; Ren, X.; Li, J.; Thompson, M. E. Appl. Phys. Lett. 2003, 83, 3818. (e) Tanaka, I.; Tabata, Y.; Tokito, S. Chem. Phys. Lett. 2004, 400, 86.

(6) (a) Anderson, P. A.; Keene, F. R.; Meyer, T. J.; Moss, J. A.; Strouse, G. F.; Treadway, J. A. J. Chem. Soc., Dalton Trans. 2002, 3820. (b) Koike, K.; Okoshi, N.; Hori, H.; Takeuchi, K.; Ishitani, O.; Tsubaki, H.; Clark, I. P.; George, M. W.; Johnson, F. P. A.; Turner, J. J. J. Am. Chem. Soc. 2002, 124, 11448.

(7) (a) Lee, C.-L.; Das, R. R.; Kim, J.-J. Chem. Mater. 2004, 16, 4642. (b) Nazeeruddin, M. K.; Humphry-Baker, R.; Berner, D.; Rivier, S.; Zuppiroli, L.; Graetzel, M. J. Am. Chem. Soc. 2003, 125, 8790.

(8) (a) Yu, J.-K.; Hu, Y.-H.; Cheng, Y.-M.; Chou, P.-T.; Peng, S.-M.; Lee, G.-H.; Carty, A. J.; Tung, Y.-L.; Lee, S.-W.; Chi, Y.; Liu, C.-S Chem.-Eur. J. 2004, 10, 6255. (b) Wu, P.-C.; Yu, J.-K.; Song, Y.-H.; Chi, Y.; Chou, P.-T.; Peng, S.-M.; Lee, G.-H. Organometallics $\mathbf{2 0 0 3}, 22,4938$.

(9) Sajoto, T.; Djurovich, P. I.; Tamayo, A.; Yousufuddin, M.; Bau, R.; Thompson, M. E.; Holmes, R. J.; Forrest, S. R. Inorg. Chem. 2005 , 44, 7992. saturated blue color or even near-UV phosphorescence. ${ }^{10}$ Despite this perspective, however, almost all of these blue phosphorescent complexes are inevitably subject to a pronounced decrease in the luminance efficiency at room temperature.

Because both strong-field metal elements and ligands are selected in assembling this class of metal complexes, it is reasonable to expect that the metal-centered dd state will be inaccessible from the lowest emissive triplet state. Thus, the dominant radiationless deactivation generalized by a quenching mechanism incorporating dd transition may be groundless. ${ }^{6,11}$ As such, the call for alternative, convincing explanations to account for this ubiquitous observation is urgent. Bearing this challenge in mind, we then made an assiduous effort to design and synthesize a new series of $\mathrm{Ru}^{\mathrm{II}}$ complexes possessing cyclometalated chromophores and other strongfield ligands, aimed at probing the radiationless pathways in correlation with their chemical structures. ${ }^{12}$ It is notable that $\mathrm{Ru}^{\mathrm{II}}$ complexes are well suited for this approach mainly because of their relatively small ligand field and weaker metal-ligand bonding. This, in combination with its less heavy atom effect and hence the weaker spin-orbit coupling, leads us to believe that, under the same ligand configuration, the induction of radiationless transition in $\mathrm{Ru}^{\mathrm{II}}$ complexes is expected to be more drastic than that of the third-row metal congeners. Accordingly, it becomes more plausible to explore the undermining factors causing such intriguing phenomena, i.e., loss of the emission intensity, from fundamental aspects. As an equally important issue, once the radiationless channels are inhibited, the prevailing of $\mathrm{Ru}^{\mathrm{II}}$ complexes to the thirdrow transition-metal complexes toward OLED application are apparently due to the lower cost and greater abundance of $\mathrm{Ru}$.

\section{Experimental Section}

General Information and Materials. Elemental analyses and mass spectroscopy (operating in fast atom bombardment, FAB, mode) were carried out at the NSC Regional Instrument Centre at National Chiao Tung University, Hsinchu, Taiwan. ${ }^{1} \mathrm{H}$ and ${ }^{13} \mathrm{C}$ NMR spectra were recorded on a Varian Mercury 400 or an Inova $500-\mathrm{MHz}$ instrument; chemical shifts are quoted with respect to internal standard $\mathrm{Me}_{4} \mathrm{Si}$. Details of the fabrication and characterization of electroluminescent devices are as reported previously. ${ }^{1 \mathrm{~b}}$ All synthetic manipulations were performed under a $\mathrm{N}_{2}$ atmosphere, while solvents were used as received. Benzo[ $h]$ quinoline (BQ) was purchased from TCI Japan, while dibenzo[f,h]quinoxaline (DBQ) was prepared from condensation of phenanthrene-9,10-dione with ethylenediamine. ${ }^{13}$ The $\mathrm{Ru}^{\mathrm{II}}$ metal complex $\left[\mathrm{Ru}(\mathrm{CO})_{2}(\mathrm{BQ})_{2}\right](\mathbf{1})$ was

(10) (a) Li, J.; Djurovich, P. I.; Alleyne, B. D.; Tsyba, I.; Ho, N. N.; Bau, R.; Thompson, M. E. Polyhedron 2004, 23, 419. (b) Yang, C.-H.; Li, S.-W.; Chi, Y.; Cheng, Y.-M.; Yeh, Y.-S.; Chou, P.-T.; Lee, G.-H.; Wang, C.-H.; Shu, C.-F. Inorg. Chem. 2005, 44, 7770. (c) Li, J.; Djurovich, P. I.; Alleyne, B. D.; Yousufuddin, M.; Ho, N. N.; Thomas, J. C.; Peters, J. C.; Bau, R.; Thompson, M. E. Inorg. Chem. 2005, 44 1713.

(11) Zalis, S.; Farrell, I. R.; Vlcek, A. J. Am. Chem. Soc. 2003, 125, 4580

(12) Tung, Y.-L.; Chen, L.-S.; Chi, Y.; Chou, P.-T.; Cheng, Y.-M.; Li, E. Y.; Lee, G.-H.; Shu, C.-F.; Wu, F.-I.; Carty, A. J. Adv. Funct. Mater. 2006, 16, 1615.

(13) Steel, P. J.; Caygill, G. B. J. Organomet. Chem. 1990, 395, 359. 
prepared using $\mathrm{Ru}_{3}(\mathrm{CO})_{12}$ and $\mathrm{BQ}$ in a mixture of 1,2-dimethoxyethane and octane following literature procedures. ${ }^{14}$

Cyclic voltammetry (CV) measurements were performed using a BAS $100 \mathrm{~B} / \mathrm{W}$ electrochemical analyzer. The oxidation and reduction measurements were recorded, respectively, in anhydrous $\mathrm{CH}_{2} \mathrm{Cl}_{2}$ and anhydrous THF solutions containing $0.1 \mathrm{M} \mathrm{TBAPF}_{6}$ as the supporting electrolyte, at a scan rate of $100 \mathrm{mV} \mathrm{s}^{-1}$. The potentials were measured against an $\mathrm{Ag} / \mathrm{Ag}^{+}\left(0.01 \mathrm{M} \mathrm{AgNO}_{3}\right)$ reference electrode with the ferrocene/ferrocenium couple as the internal standard.

Steady-state absorption and emission spectra were recorded by a Hitachi U-3310 spectrophotometer and an Edinburgh FS920 fluorimeter, respectively. Emission quantum yields were measured at excitation wavelength $\lambda_{\text {exc }}=480 \mathrm{~nm}$ in $\mathrm{CH}_{2} \mathrm{Cl}_{2}$ at room temperature. 4-(Dicyanomethylene)-2-methyl-6-[ $p$-(dimethylamino)styryl]-4H-pyran $\left(\mathrm{DCM}, \Phi_{\mathrm{r}}=0.44\right)$ in a methanol solution was used as the reference, and the equation

$$
\Phi_{\mathrm{s}}=\Phi_{\mathrm{r}}\left(\frac{\eta_{\mathrm{s}}^{2} A_{\mathrm{r}} I_{\mathrm{s}}}{\eta_{\mathrm{r}}^{2} A_{\mathrm{s}} I_{\mathrm{r}}}\right)
$$

was used to calculate the emission quantum yields, where $\Phi_{\mathrm{s}}$ and $\Phi_{\mathrm{r}}$ are the quantum yields of the unknown and reference samples, $\eta$ is the refractive index of the solvent, $A_{\mathrm{r}}$ and $A_{\mathrm{s}}$ are the absorbance of the reference and the unknown samples at the excitation wavelength, and $I_{\mathrm{s}}$ and $I_{\mathrm{r}}$ are the integrated areas under the emission spectra of interest, respectively. For the phosphorescence lifetime measurements in the microsecond region, a third harmonic of an Nd:YAG laser of $355 \mathrm{~nm}$ was used as the excitation source. For this approach, emission decay was detected with a photomultiplier tube and averaged over 500 shots using an oscilloscope, and laser energy was reduced to $\leq 1 \mathrm{~mJ}$ pulse $^{-1}$ to prevent possible photochemical decomposition. For the nanosecond lifetime measurements, the fundamental train of pulses from a Ti-sapphire oscillator (82 MHz, Spectra Physics) was used to produce second harmonics $(375-425 \mathrm{~nm})$ as an excitation light source. The signal was detected by a time-correlated single-photon-counting system (Edinburgh OB 900-L).

Synthesis of $\left[\mathrm{Ru}(\mathrm{CO})_{2}(\mathrm{DBQ})_{2}\right]$ (2). A mixture of $\mathrm{Ru}_{3}(\mathrm{CO})_{12}$ (111 mg, $017 \mathrm{mmol})$, dibenzo[f,h]quinoline (250 mg, $1.09 \mathrm{mmol})$, 1,2-dimethoxyethane $(2 \mathrm{~mL})$, and octane $(15 \mathrm{~mL})$ was heated at reflux for $12 \mathrm{~h}$, after which time a dark-brown precipitate had deposited from the brown solution. The solvent was then removed using a rotary evaporator, and the residue was treated with a mixture of $1 \mathrm{~mL}$ of diethylamine and $3 \mathrm{~mL}$ of methanol to remove the probable side product $\left[\mathrm{Ru}_{4} \mathrm{H}_{4}(\mathrm{CO})_{12}\right]$. The remaining solid was collected by filtration and washed with methanol $(3 \times 2 \mathrm{~mL})$ and hexane $(3 \times 3 \mathrm{~mL})$ three times. The expected DBQ complex 2 was obtained as a yellow-brown solid $(83 \mathrm{mg}, 0.34 \mathrm{mmol}$, $80 \%)$.

Spectral Data of 2. MS (FAB, $\left.{ }^{102} \mathrm{Ru}\right)$ : observed $\mathrm{m} / \mathrm{z}$ [assignment] $616\left[\mathrm{M}^{+}\right]$. IR $\left(\mathrm{CH}_{2} \mathrm{Cl}_{2}\right): v(\mathrm{CO}) 2015(\mathrm{~s}), 1948(\mathrm{~s}) \mathrm{cm}^{-1} \cdot{ }^{1} \mathrm{H}$ NMR (400 MHz, $\left.\mathrm{CD}_{2} \mathrm{Cl}_{2}\right): \delta 9.04(\mathrm{~d}, 2 \mathrm{H}, J=7.6 \mathrm{~Hz}), 8.73(\mathrm{~d}$, $2 \mathrm{H}, J=8.4 \mathrm{~Hz}), 8.55(\mathrm{~d}, 2 \mathrm{H}, J=7.2 \mathrm{~Hz}), 8.45(\mathrm{~d}, 2 \mathrm{H}, J=8.0$ $\mathrm{Hz}), 8.37(\mathrm{~d}, 2 \mathrm{H}, J=2.8 \mathrm{~Hz}), 7.90-7.81(\mathrm{~m}, 4 \mathrm{H}), 7.77(\mathrm{~d}, 2 \mathrm{H}, J$ $=2.8 \mathrm{~Hz}), 7.70(\mathrm{t}, 2 \mathrm{H}, J=7.6 \mathrm{~Hz})$. Anal. Calcd for $\mathrm{C}_{34} \mathrm{H}_{18} \mathrm{~N}_{4} \mathrm{O}_{2^{-}}$ Ru: C, 66.34; H, 2.95; N, 9.10. Found: C, 66.37; H, 3.01; N, 8.95.

Preparation of $\left[\mathbf{R u}(\mathbf{C O})(\mathbf{B Q})_{2}\left(\mathbf{P P h}_{2} \mathbf{M e}\right)\right](3)$. A 50-mL reaction flask was first charged with 1 (300 mg, $0.58 \mathrm{mmol})$ and $20 \mathrm{~mL}$ of

(14) (a) Patrick, J. M.; White, A. H.; Bruce, M. I.; Beatson, M. J.; Black, D. S. C.; Deacon, G. B.; Thomas, N. C. J. Chem. Soc., Dalton Trans. 1983, 2121. (b) Bruce, M. I.; Liddell, M. J.; Pain, G. N. Inorg. Synth. 1989, 26, 171 . anhydrous diethylene glycol monoethyl ether (DGME) and then immersed into an oil bath maintained at $\sim 130^{\circ} \mathrm{C}$. Freshly sublimed $\mathrm{Me}_{3} \mathrm{NO}$ (109 mg, $1.46 \mathrm{mmol}$ ) dissolved in $12 \mathrm{~mL}$ of DGME was dropwise added over a period of $5 \mathrm{~min}$, followed by the addition of $\mathrm{PPh}_{2} \mathrm{Me}(500 \mu \mathrm{L}, 2.63 \mathrm{mmol})$. The resulting mixture was then stirred at $160{ }^{\circ} \mathrm{C}$ for $24 \mathrm{~h}$. Finally, the solvent was evaporated under vacuum and the residue placed into $30 \mathrm{~mL}$ of $\mathrm{CH}_{2} \mathrm{Cl}_{2}$. The solution was washed with distilled water $(150 \mathrm{~mL} \times 2)$, dried over $\mathrm{MgSO}_{4}$, and evaporated to dryness. The residue was purified by silica gel column chromatography using ethyl acetate/hexane (1:5) as the eluent. Recrystallization was conducted from a mixture of $\mathrm{CH}_{2} \mathrm{Cl}_{2}$ and methanol at room temperature, giving yellow crystalline solids $(238 \mathrm{mg}, 0.348 \mathrm{mmol})$ in $60 \%$ yield. Complex $\left[\mathrm{Ru}(\mathrm{CO})(\mathrm{BQ})_{2-}\right.$ $\left.\left(\mathrm{PPhMe}_{2}\right)\right]$ (4) was prepared in $80 \%$ yield using similar procedures.

Spectral Data for 3. MS (FAB, ${ }^{102} \mathrm{Ru}$ ): observed $\mathrm{m} / \mathrm{z}$ [assignment] $686\left[\mathrm{M}^{+}\right]$. IR $\left(\mathrm{CH}_{2} \mathrm{Cl}_{2}\right): v(\mathrm{CO}) 1909(\mathrm{~s}) \mathrm{cm}^{-1} .{ }^{1} \mathrm{H}$ NMR $\left(500 \mathrm{MHz}\right.$, acetone- $\left.d_{6}\right): \delta 9.01(\mathrm{dd}, 1 \mathrm{H}, J=5.0$ and $1.0 \mathrm{~Hz}), 8.52$ $(\mathrm{dd}, 1 \mathrm{H}, J=1.5$ and $1.0 \mathrm{~Hz}), 8.30-8.29(\mathrm{~m}, 1 \mathrm{H}), 7.85(\mathrm{~d}, 1 \mathrm{H}, J$ $=7.8 \mathrm{~Hz}), 7.78-7.67(\mathrm{~m}, 5 \mathrm{H}), 7.56-7.40(\mathrm{~m}, 7 \mathrm{H}), 7.27(\mathrm{~d}, 1 \mathrm{H}, J$ $=7.5 \mathrm{~Hz}) 7.02-6.81(\mathrm{~m}, 6 \mathrm{H}), 6.70(\mathrm{dd}, 1 \mathrm{H}, J=8.0$ and $5.5 \mathrm{~Hz})$, $6.64-6.60(\mathrm{~m}, 2 \mathrm{H}), 1.32(\mathrm{~d}, 3 \mathrm{H}, J=6.5 \mathrm{~Hz}) .{ }^{31} \mathrm{P}$ NMR $(202 \mathrm{MHz}$, acetone- $d_{6}$ ): $\delta 18.35$ (s). Anal. Calcd for $\mathrm{C}_{40} \mathrm{H}_{29} \mathrm{~N}_{2} \mathrm{OPRu}$ : C, 70.06; H, 4.26; N, 4.09. Found: C, 69.75; H, 4.57; N, 4.01.

Spectral Data for 4. MS (FAB, $\left.{ }^{102} \mathrm{Ru}\right)$ : observed $\mathrm{m} / \mathrm{z}$, assignment] $624\left[\mathrm{M}^{+}\right]$. IR $\left(\mathrm{CH}_{2} \mathrm{Cl}_{2}\right): v(\mathrm{CO}) 1909$ (s) $\mathrm{cm}^{-1} .{ }^{1} \mathrm{H}$ NMR $\left(400 \mathrm{MHz}, \mathrm{CD}_{2} \mathrm{Cl}_{2}\right): \delta 8.42(\mathrm{dt}, 1 \mathrm{H}, J=5.6$ and $1.6 \mathrm{~Hz}), 8.35(\mathrm{~d}$, $1 \mathrm{H}, J=5.2 \mathrm{~Hz}), 8.26(\mathrm{dd}, 1 \mathrm{H}, J=6.6$ and $1.6 \mathrm{~Hz}), 7.91(\mathrm{~d}, 1 \mathrm{H}$, $J=8.0 \mathrm{~Hz}), 7.82(\mathrm{~d}, 1 \mathrm{H}, J=8.8 \mathrm{~Hz}), 7.00(\mathrm{~d}, 1 \mathrm{H}, J=8.8 \mathrm{~Hz})$, $7.64-7.54(\mathrm{~m}, 3 \mathrm{H}), 7.47(\mathrm{~d}, 1 \mathrm{H}, J=8.8 \mathrm{~Hz}), 7.30-7.23(\mathrm{~m}, 7 \mathrm{H})$, $7.13(\mathrm{dt}, 1 \mathrm{H}, J=4.8$ and $1.6 \mathrm{~Hz}), 6.98(\mathrm{td}, 1 \mathrm{H}, J=7.4$ and 1.2 $\mathrm{Hz}), 6.95-6.83(\mathrm{~m}, 2 \mathrm{H}), 1.56(\mathrm{~d}, 3 \mathrm{H}, J=7.2 \mathrm{~Hz}), 0.61$ (d, 3H, $J$ $=6.4 \mathrm{~Hz}) \cdot{ }^{31} \mathrm{P}$ NMR $\left(202 \mathrm{MHz}, \mathrm{CDCl}_{3}\right): \delta 18.32(\mathrm{~s})$. Anal. Calcd for $\mathrm{C}_{35} \mathrm{H}_{27} \mathrm{~N}_{2} \mathrm{OPRu}$ : C, 67.41; $\mathrm{H}, 4.36$; $\mathrm{N}, 4.49$. Found: C, 67.52; H, 4.46; N, 4.74.

Preparation of $\left[\mathrm{Ru}(\mathrm{CO})(\mathrm{DBQ})_{2}\left(\mathrm{PPh}_{2} \mathrm{Me}\right)\right](5)$ and $[\mathrm{Ru}(\mathrm{CO})$ $\left.(\mathbf{D B Q})_{2}\left(\mathbf{P P h M e}_{2}\right)\right](\mathbf{6})$. The synthesis procedures were essentially identical with those described for $\mathbf{3}$, using similar ratios of $\mathbf{1}$, freshly sublimed $\mathrm{Me}_{3} \mathrm{NO}$, and the phosphine ligand $\mathrm{PPh}_{2} \mathrm{Me}$ or $\mathrm{PPhMe}_{2}$. Dark-red 5 and $\mathbf{6}$ were obtained from a mixture of $\mathrm{CH}_{2} \mathrm{Cl}_{2}$ and methanol at room temperature. Yield: $68-70 \%$.

Spectral Data for 5. MS $\left(\mathrm{FAB},{ }^{102} \mathrm{Ru}\right)$ : observed $\mathrm{m} / \mathrm{z}$ [assignment $788\left[\mathrm{M}^{+}\right]$. IR $\left(\mathrm{CH}_{2} \mathrm{Cl}_{2}\right): v(\mathrm{CO}) 1928(\mathrm{~s}) \mathrm{cm}^{-1} .{ }^{1} \mathrm{H}$ NMR $\left(400 \mathrm{MHz}, \mathrm{CD}_{2} \mathrm{Cl}_{2}\right): \delta 9.22(\mathrm{dd}, 1 \mathrm{H}, J=7.8$ and $1.6 \mathrm{~Hz}), 8.91(\mathrm{~d}$, $1 \mathrm{H}, J=8.0 \mathrm{~Hz}), 8.77-8.75(\mathrm{~m}, 2 \mathrm{H}), 8.69(\mathrm{~d}, 1 \mathrm{H}, J=8.0 \mathrm{~Hz})$, $8.52(\mathrm{~d}, 1 \mathrm{H}, J=7.6 \mathrm{~Hz}), 8.41(\mathrm{~d}, 1 \mathrm{H}, J=7.6 \mathrm{~Hz}), 8.23(\mathrm{~d}, 1 \mathrm{H}$, $J=8.0 \mathrm{~Hz}), 7.98(\mathrm{~d}, 1 \mathrm{H}, J=8.0 \mathrm{~Hz}), 7.86-7.44(\mathrm{~m}, 11 \mathrm{H}), 7.10-$ $7.06(\mathrm{~m}, 2 \mathrm{H}), 6.91-6.90(\mathrm{~m}, 1 \mathrm{H}), 6.76-6.69(\mathrm{~m}, 3 \mathrm{H}), 6.56-6.52$ $(\mathrm{m}, 2 \mathrm{H}), 1.41(\mathrm{~d}, 3 \mathrm{H}, J=7.5 \mathrm{~Hz}) .{ }^{31} \mathrm{P}$ NMR $\left(202 \mathrm{MHz}, \mathrm{CDCl}_{3}\right)$ : $\delta 18.26$ (s). Anal. Calcd for $\mathrm{C}_{46} \mathrm{H}_{31} \mathrm{~N}_{4} \mathrm{OPRu}$ : C, 70.13; H, 3.97; N, 7.11. Found: C, 69.86; H, 3.71; N, 6.41.

Spectral Data for 6. MS (FAB, $\left.{ }^{102} \mathrm{Ru}\right)$ : observed $\mathrm{m} / \mathrm{z}$ [assignment] $726\left[\mathrm{M}^{+}\right]$. IR $\left(\mathrm{CH}_{2} \mathrm{Cl}_{2}\right): v(\mathrm{CO}) 1924(\mathrm{~s}) \mathrm{cm}^{-1} .{ }^{1} \mathrm{H}$ NMR $\left(500 \mathrm{MHz}, \mathrm{CD}_{2} \mathrm{Cl}_{2}\right): \delta 9.21(\mathrm{dd}, 1 \mathrm{H}, J=7.8$ and $1.0 \mathrm{~Hz}), 8.99$ $(\mathrm{dd}, 1 \mathrm{H}, J=7.8$ and $1.0 \mathrm{~Hz}), 8.86(\mathrm{~d}, 1 \mathrm{H}, J=2.4 \mathrm{~Hz}), 8.81(\mathrm{~d}$, $1 \mathrm{H}, J=8.3 \mathrm{~Hz}), 8.70(\mathrm{~d}, 1 \mathrm{H}, J=3.0 \mathrm{~Hz}), 8.60(\mathrm{~d}, 1 \mathrm{H}, J=8.5$ $\mathrm{Hz}), 8.45(\mathrm{~d}, 1 \mathrm{H}, J=7.0 \mathrm{~Hz}), 8.32(\mathrm{~d}, 1 \mathrm{H}, J=8.0 \mathrm{~Hz}), 8.25(\mathrm{~d}$, $1 \mathrm{H}, J=2.5 \mathrm{~Hz}), 8.00(\mathrm{~d}, 1 \mathrm{H}, J=7.5 \mathrm{~Hz}), 7.86-7.67(\mathrm{~m}, 5 \mathrm{H})$, $7.49(\mathrm{dd}, 1 \mathrm{H}, J=2.5$ and $1.0 \mathrm{~Hz}), 7.22-6.89(\mathrm{~m}, 7 \mathrm{H}), 1.76(\mathrm{~d}$, $3 \mathrm{H}, J=7.5 \mathrm{~Hz}), 1.03(\mathrm{~d}, 3 \mathrm{H}, J=7.5 \mathrm{~Hz}) .{ }^{31} \mathrm{P} \mathrm{NMR}(202 \mathrm{MHz}$, $\mathrm{CD}_{2} \mathrm{Cl}_{2}$ ): $\delta 18.22$ (s). Anal. Calcd for $\mathrm{C}_{41} \mathrm{H}_{29} \mathrm{~N}_{4} \mathrm{OPRu}$ : C, 67.85; H, 4.03; N, 7.72. Found: C, 68.17; H, 4.36; N, 7.94.

X-ray Structural Measurements. Single-crystal X-ray analysis was measured on a Bruker SMART Apex CCD diffractometer using 


\section{Li et al.}

Table 1. X-ray Structural Data of Complex 3

\begin{tabular}{|c|c|}
\hline empirical formula & $\mathrm{C}_{40} \mathrm{H}_{29} \mathrm{~N}_{2} \mathrm{OPRu}$ \\
\hline mol wt & 685.69 \\
\hline cryst syst & monoclinic \\
\hline space group & $P 2_{1} / c$ \\
\hline$T, \mathrm{~K}$ & $150(1)$ \\
\hline$a, \AA$ & $9.5823(5)$ \\
\hline$b, \AA$ & 17.7987(10) \\
\hline$c, \AA$ & $18.2986(10)$ \\
\hline$\beta, \operatorname{deg}$ & $96.148(1)$ \\
\hline$V, \AA^{3}$ & $3102.9(3)$ \\
\hline$Z$ & 4 \\
\hline$D_{\mathrm{c}}, \mathrm{g} \mathrm{cm}^{-3}$ & 1.468 \\
\hline$F(000)$ & 1400 \\
\hline$\mu(\mathrm{Mo} \mathrm{K} \alpha), \mathrm{mm}^{-1}$ & 0.593 \\
\hline cryst size, mm & $0.30 \times 0.25 \times 0.20$ \\
\hline$h, k, l$ ranges & $\begin{array}{l}-11<h<12 \\
-23<k<23 \\
-23<l<23\end{array}$ \\
\hline reflns collected & 25478 \\
\hline indep reflns & $7127[R($ int $)=0.0375]$ \\
\hline data/restraints/parameters & $7127 / 0 / 407$ \\
\hline GOF on $F^{2}$ & 1.110 \\
\hline R1, wR2 with $I>2 \sigma(I)$ & $0.0348,0.0840$ \\
\hline D map, max $/ \min , \mathrm{e} / \AA^{-3}$ & $0.510 /-0.384$ \\
\hline
\end{tabular}

Table 2. Selected Bond Distances ( $\AA$ ) and Angles (deg) for Complex 3

\begin{tabular}{llll}
\hline $\mathrm{Ru}-\mathrm{P}(1)$ & $2.3789(6)$ & $\mathrm{Ru}-\mathrm{C}(1)$ & $1.833(3)$ \\
$\mathrm{Ru}-\mathrm{C}(2)$ & $2.079(2)$ & $\mathrm{Ru}-\mathrm{C}(15)$ & $2.041(2)$ \\
$\mathrm{Ru}-\mathrm{N}(1)$ & $2.208(2)$ & $\mathrm{Ru}-\mathrm{N}(2)$ & $2.151(2)$ \\
$\mathrm{C}(1)-\mathrm{O}(1)$ & $1.157(3)$ & & \\
& & & \\
$\angle \mathrm{P}(1)-\mathrm{Ru}-\mathrm{C}(2)$ & $176.09(6)$ & $\angle \mathrm{N}(1)-\mathrm{Ru}-\mathrm{C}(15)$ & $165.80(8)$ \\
$\angle \mathrm{N}(2)-\mathrm{Ru}-\mathrm{C}(1)$ & $170.34(9)$ & $\angle \mathrm{N}(1)-\mathrm{Ru}-\mathrm{C}(2)$ & $78.58(8)$ \\
$\angle \mathrm{N}(2)-\mathrm{Ru}-\mathrm{C}(15)$ & $80.10(8)$ & $\angle \mathrm{Ru}-\mathrm{C}(1)-\mathrm{O}(1)$ & $176.1(2)$
\end{tabular}

$\mu($ Mo $\mathrm{K} \alpha)$ radiation $(\lambda=0.71073 \AA)$. The data collection was executed using the SMART program. Cell refinement and data reduction were made by the SAINT program. The structure was determined using the SHELXTL/PC program and refined using fullmatrix least squares. All non-H atoms were refined anisotropically, whereas $\mathrm{H}$ atoms were placed at the calculated positions and included in the final stage of refinements with fixed parameters. The crystallographic refinement parameters of $\mathbf{3}$ are summarized in Table 1, and the selective bond distances and angles are listed in Table 2.

Theoretical Approach. Time-dependent density functional theory (TDDFT) ${ }^{15}$ calculations using the B3LYP ${ }^{16}$ functional were performed based on the structures obtained from single-crystal X-ray diffraction data. A "double- $\zeta$ " quality basis set consisting of Hay and Wadt's effective core potentials (ECPs; LANL2DZ) ${ }^{17}$ was employed for $\mathrm{Ru}$ atoms and the 6-31G* basis $\operatorname{set}^{18}$ for $\mathrm{H}, \mathrm{C}, \mathrm{N}$, and $\mathrm{P}$ atoms. A relativistic ECP replaced the inner-core electrons of $\mathrm{Ru}^{\mathrm{II}}$, leaving the outer-core $\left(4 \mathrm{~s}^{2} 4 \mathrm{p}^{6}\right)$ electrons and the $4 \mathrm{~d}^{6}$ valence electrons. Typically, the lowest 10 triplet and 10 singlet roots of

(15) (a) Jamorski, C.; Casida, M. E.; Salahub, D. R. J. Chem. Phys. 1996, 104, 5134. (b) Petersilka, M.; Grossmann, U. J.; Gross, E. K. U. Phys. Rev. Lett. 1996, 76, 1212. (c) Bauernschmitt, R.; Ahlrichs, R.; Hennrich, F. H.; Kappes, M. M. J. Am. Chem. Soc. 1998, 120, 5052. (d) Casida, M. E. J. Chem. Phys. 1998, 108, 4439. (e) Stratmann, R. E.; Scuseria, G. E.; Frisch, M. J. J. Chem. Phys. 1998, 109, 8218.

(16) (a) Lee, C.; Yang, W.; Parr, R. G. Phys. Rev. B 1988, 37, 785. (b) Becke, A. D. J. Chem. Phys. 1993, 98, 5648.

(17) (a) Hay, P. J.; Wadt, R. W. J. Chem. Phys. 1985, 82, 270. (b) Wadt, W. R.; Hay, P. J. J. Chem. Phys. 1985, 82, 284. (c) Hay, P. J.; Wadt, W. R. J. Chem. Phys. 1985, 82, 299.

(18) Hariharan, P. C.; Pople, J. A. Mol. Phys. 1974, 27, 209. the nonhermitian eigenvalue equations were obtained to determine the vertical excitation energies. Oscillator strengths were deduced from the dipole transition matrix elements (for singlet states only). The excited-state TDDFT calculations were carried out using Gaussian03, as described in our previous publications. ${ }^{19}$

\section{Results}

Synthesis and Characterization. It has been reported that the direct reaction of $\mathrm{BQ}$ with $\mathrm{Ru}_{3}(\mathrm{CO})_{12}$ in a mixture of 1,2-dimethoxyethane and octane yielded a cyclometalated $\mathrm{Ru}^{\mathrm{II}}$ complex $\mathbf{1}$, which contains two mutually orthogonal $\mathrm{C}, \mathrm{N}$-chelating BQ ligands (see Scheme 1). ${ }^{14}$ The X-ray structural analysis of $\mathbf{1}$ revealed that the central $\mathrm{Ru}$ atom has approximate octahedral coordination, for which the two mutually cis $\mathrm{CO}$ ligands lie trans to the $\mathrm{N}$ atoms of the cyclometalated BQ ligands and the cyclometalated $\mathrm{C}$ atoms are located at the opposite dispositions.

Moreover, treatment of a more conjugated heteroaromatic DBQ with $\mathrm{Ru}_{3}(\mathrm{CO})_{12}$ under similar conditions led to the isolation of a second derivative complex $\mathbf{2}$. The structure of 2 was readily characterized by NMR analyses, the results of which revealed several multiplets between $\delta 9.94$ and 7.70 due to the aromatic proton resonances, while its final structural identification was achieved by the observation of two sharp IR $v(\mathrm{CO})$ stretching bands at 2015 and $1948 \mathrm{~cm}^{-1}$, attributed to the cis-oriented $\mathrm{CO}$ ligands. To the best of our understanding, complex $\mathbf{2}$ is one of the few known examples to contain cyclometalated DBQ ligands. Well-known examples include the recently reported orange-emitting complex $\left[\operatorname{Ir}(\mathrm{DBQ})_{2}(\mathrm{acac})\right]$, for which the $\mathrm{N}$ atoms in two DBQ ligand chelates are located at the mutual trans disposition. ${ }^{20}$ In sharp contrast, however, $\mathrm{Ru}^{\mathrm{II}}$ complexes $\mathbf{1}$ and $\mathbf{2}$ possess a cis orientation between the two DBQ $\mathrm{N}$ atoms.

For preparation of the luminescent complexes (vide infra), phosphine-substituted $\mathrm{Ru}^{\mathrm{II}}$ derivatives $\mathbf{3}-\mathbf{6}$ were synthesized in two consecutive steps, employing an excess of decarbonylation reagent $\mathrm{Me}_{3} \mathrm{NO}$, followed by addition of the phosphine ligand. The resulting mixture was then stirred at $160{ }^{\circ} \mathrm{C}$ for $24 \mathrm{~h}$, and the product was isolated by routine chromatography and recrystallization. These metal complexes were found to be highly soluble in most organic solvents such as acetone and $\mathrm{CHCl}_{3}$ and have been characterized using various spectroscopic methods including FAB MS, IR, and ${ }^{1} \mathrm{H}$ and ${ }^{31} \mathrm{P}$ NMR (see the Experimental Section). Importantly, these complexes showed only one sharp IR $v(\mathrm{CO})$ stretching signal in the range $1928-1909 \mathrm{~cm}^{-1}$ and are in good agreement with the retention of a single carbonyl ligand. It is also notable that the amount of $\mathrm{Me}_{3} \mathrm{NO}$ added in the initial reaction mixture is sufficient to remove both $\mathrm{CO}$ ligands in the parent complexes $\mathbf{1}$ and $\mathbf{2}$; this observation implies that the second, remaining $\mathrm{CO}$ ligand is essentially inert to the $\mathrm{Me}_{3} \mathrm{NO}$ reagent.

Figure 1 depicts the ORTEP diagram of $\mathbf{3}$, showing octahedral arrangement around the $\mathrm{Ru}^{\mathrm{II}}$ metal center. However, to our surprise, the $\mathrm{BQ}$ ligand orientation is distinctive from

(19) Yu, J.-K.; Cheng, Y.-M.; Hu, Y.-H.; Chou, P.-T.; Chen, Y.-L.; Lee, S.-W.; Chi, Y. J. Phys. Chem. B 2004, 108, 19908.

(20) Duan, J.-P.; Sun, P.-P.; Cheng, C.-H. Adv. Mater. 2003, 15, 224. 


\section{Scheme 1}

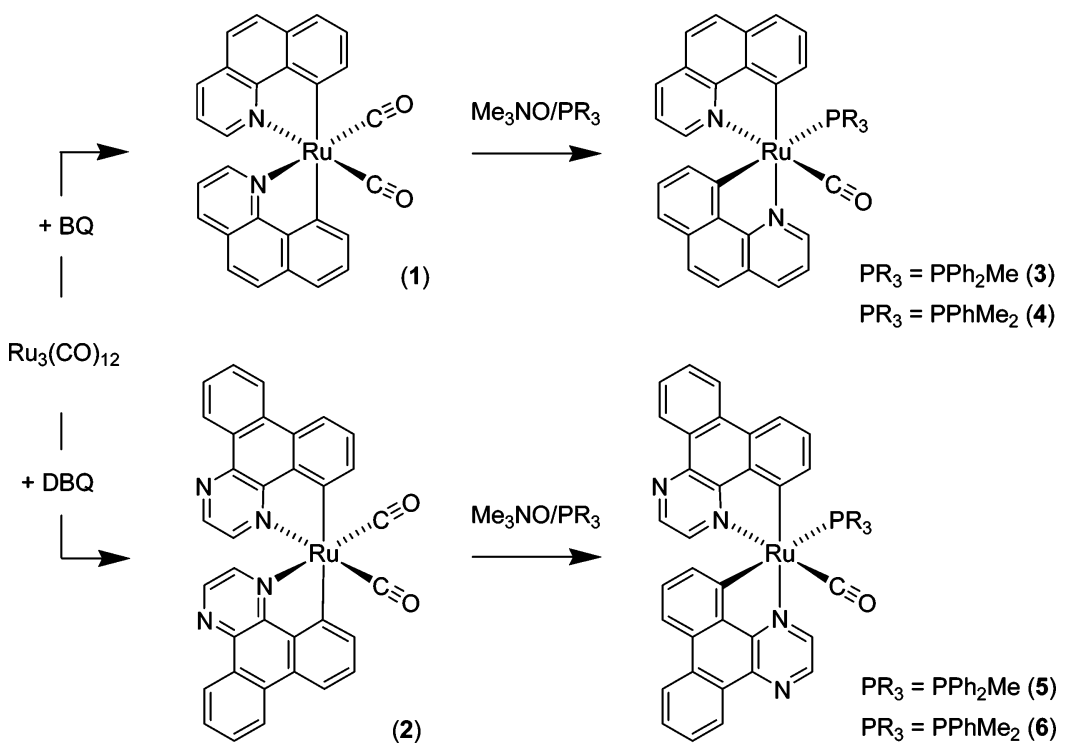

that of its parent complex $\mathbf{1}$, namely, one cyclometalated C atom is shifted to a new position trans to the $\mathrm{PPh}_{2} \mathrm{Me}$ phosphine ligand, while the second $\mathrm{C}$ atom resides trans to the $\mathrm{N}$ atom of the second $\mathrm{BQ}$ ligand. This unique structural behavior demonstrates that one BQ ligand undergoes a $180^{\circ}$ rotation around the $\mathrm{Ru}^{\mathrm{II}}$ center during the course of phosphine substitution. A similar coordination arrangement was observed from the X-ray structural determination of a $\mathrm{PPh}_{3}$ derivative prepared using UV irradiation. ${ }^{21}$

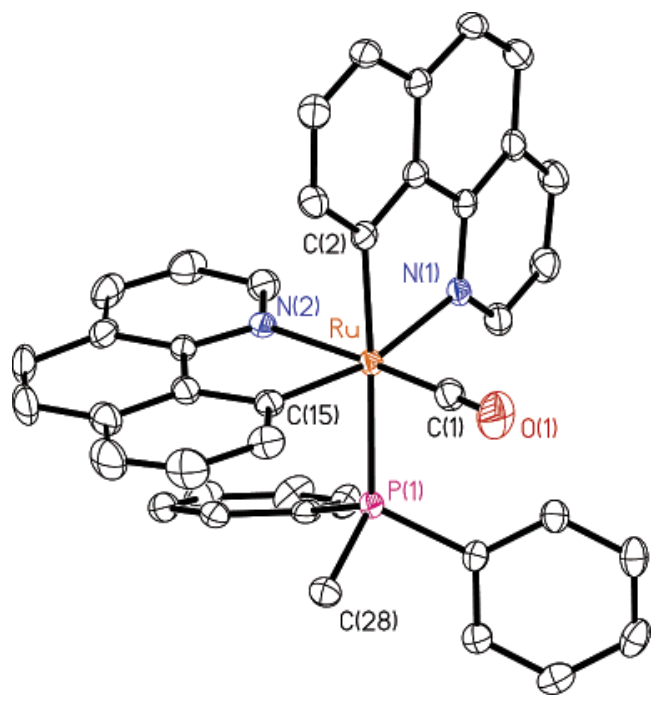

Figure 1. ORTEP diagram of $\mathbf{3}$ with thermal ellipsoids shown at the $50 \%$ probability level.

For the metric parameters, in $\mathbf{3}$, the $\mathrm{Ru}-\mathrm{N}(1)$ distance [2.208(2) $\AA]$ of the first BQ ligand is obviously longer than the respective $\mathrm{Ru}-\mathrm{N}(2)$ distance [2.151(2) $\AA$ ] and the $\mathrm{Ru}-\mathrm{N}$ distances observed in $\mathbf{1}$ (2.148 and $2.161 \AA$ ), showing a large labilization effect attributed to its trans $\mathrm{Ru}-\mathrm{C}(15) \sigma$ bond versus that of the trans $\mathrm{CO}$ ligand exerted to the second $\mathrm{BQ}$

(21) Zhang, Q.-F.; Cheung, K.-M.; Williams, I. D.; Leung, W.-H. Eur. J. Inorg. Chem. 2005, 4780. ligand. Apparently, the trans competition through metal-C $\sigma$ bonding is more pronounced in this class of complexes, although the CO ligand was among the best $\pi$-acceptor ligands but has failed to impose a sufficient amount of trans effect compared to the metal $-\mathrm{C} \sigma$ bond that exerted to the first $\mathrm{BQ}$ ligand. Moreover, the $\mathrm{Ru}-\mathrm{C}$ distance of the second BQ ligand $[\mathrm{Ru}-\mathrm{C}(15)=2.041(2) \AA]$ is shorter than that of the other $\mathrm{Ru}-\mathrm{C}$ bond $[\mathrm{Ru}-\mathrm{C}(2)=2.079(2) \AA]$, which is, in turn, much shorter than those of the mutually trans-oriented $\mathrm{Ru}-\mathrm{C}$ bonds of its parent complex 1 [2.12-2.13(1) $\AA] .{ }^{12}$ Again, this increase in the $\mathrm{Ru}-\mathrm{C}$ bond distances could be attributed to the bonding competition exerted by their trans ligands, for which the metal-ligand bond strengths follow the order of, i.e., cyclometalated $\mathrm{C}$ atom (C) $>$ phosphine (P) $>$ pyridine $(\mathrm{N})$.

Electrochemistry. The redox potentials of the $\mathrm{Ru}^{\mathrm{II}}$ complexes were determined from cyclic voltammograms, and the data are summarized in Table 3 . It is believed that the oxidation occurred mainly at the metal site, with minor contributions from the cyclometalated chelate and other ancillary ligands. For $\mathbf{3}$ and $\mathbf{4}$ possessing BQ ligands, an oxidation potential at $0.13 \mathrm{~V}$ was acquired in $\mathrm{CH}_{2} \mathrm{Cl}_{2}$, while DBQ complexes 5 and $\mathbf{6}$ exhibited a higher oxidation potential at $0.35 \mathrm{~V}$ due to the presence of the quinoxaline fragment, which reduced the electron donation to the metal atom with the presence of an additional $\mathrm{N}$ atom. Moreover, variation of phosphine has caused almost no change to the oxidation potential. Finally, the corresponding parents $\mathbf{1}$ and 2 give an irreversible oxidation half-wave at 0.74 and 0.95 $\mathrm{V}$, which are in good agreement with their electron-deficient nature induced by the carbonyl ligands.

As for the reduction behavior, the dicarbonyl complexes $\mathbf{1}$ and $\mathbf{2}$ give three closely spaced, reversible reduction peaks in the THF solution, a result of two one-electron reductions at each of the cyclometalated ligands as well as the possible reduction at the metal site to give $\mathrm{Ru}^{\mathrm{I}}$ species. It is possible that this metal reduction is coupled with the $\left[\mathrm{Ru}(\mathrm{CO})_{2}\right]$ fragment, allowing an easy delocalization of electron density 
Li et al.

Table 3. Photophysical and Electrochemical Properties for Complexes 1-6 in Degassed $\mathrm{CH}_{2} \mathrm{Cl}_{2}$ at Room Temperature

\begin{tabular}{|c|c|c|c|c|c|c|c|}
\hline & $\lambda_{\max }^{\mathrm{abs}} / \mathrm{nm}\left(\epsilon \times 10^{-3}\right)$ & $\lambda_{\max }^{\mathrm{em}} / \mathrm{nm}$ & $\Phi$ & $k_{\mathrm{obs}}\left(\mathrm{s}^{-1}\right)$ & $k_{\mathrm{r}}\left(\mathrm{s}^{-1}\right)$ & $E_{1 / 2}^{\mathrm{ox}}$ & $E_{1 / 2}^{\mathrm{red}}$ \\
\hline 1 & $\begin{array}{l}320(7.2), 381(3.8), \\
395(4.2)\end{array}$ & $\begin{array}{c}-[485,521,563 \\
617(\mathrm{sh})]^{a}\end{array}$ & & $-\left[4.1 \times 10^{2}\right]^{a}$ & & 0.74 [irr] & $-2.41,-2.64,-2.77$ \\
\hline 2 & $\begin{array}{l}332(14), 376(7), \\
421(3.8)\end{array}$ & $562[526]^{a}$ & $\sim 5.0 \times 10^{-4}$ & $3.7 \times 10^{6}\left[7.9 \times 10^{3}\right]^{a}$ & $\sim 1.9 \times 10^{3}$ & 0.95 [irr] & $-1.91,-2.11,-2.34$ \\
\hline 3 & $\begin{array}{l}310(14), 370(7.4), \\
456(2.4)\end{array}$ & $571[553]^{a}(539)^{b}$ & 0.24 & $\begin{array}{l}1.4 \times 10^{5}\left[3.8 \times 10^{3}\right]^{a} \\
\left(2.5 \times 10^{7}\right)^{b}\end{array}$ & $3.3 \times 10^{4}$ & 0.13 & $-2.57,-2.92$ \\
\hline 4 & $\begin{array}{l}312(18), 378(9.2), \\
458(3)\end{array}$ & $575[556]^{a}(542)^{b}$ & 0.18 & $\begin{array}{l}1.2 \times 10^{5}\left[5.5 \times 10^{3}\right]^{a} \\
\left(2.0 \times 10^{7}\right)^{b}\end{array}$ & $2.1 \times 10^{4}$ & 0.13 & $-2.59,-2.86$ \\
\hline 5 & $\begin{array}{l}344(13), 359(12) \\
387(8), 506(1.4)\end{array}$ & $655[632]^{a}(642)^{b}$ & 0.008 & $\begin{array}{l}4.2 \times 10^{6}\left[1.7 \times 10^{4}\right]^{a} \\
\left(1.4 \times 10^{7}\right)^{b}\end{array}$ & $3.3 \times 10^{4}$ & 0.35 & $-2.07,-2.32$ \\
\hline 6 & $\begin{array}{l}343(11), 362(16), \\
387(11), 513(1.8)\end{array}$ & $656[633]^{a}(645)^{b}$ & 0.004 & $7.1 \times 10^{6}\left[1.8 \times 10^{4}\right]^{a}$ & $2.9 \times 10^{4}$ & 0.35 & $-2.09,-2.32$ \\
\hline
\end{tabular}

${ }^{a}$ Data in square brackets are measured in a $\mathrm{CH}_{2} \mathrm{Cl}_{2}$ matrix at $77 \mathrm{~K}$, and "sh" denotes "shoulder". ${ }^{b}$ Data in parentheses are measured in a thin solid film at room temperature.

to the CO ligands. However, no further attempt was made to support this hypothesis. On the other hand, the phosphinesubstituted complexes 3-6 exhibit only two reversible reduction signals between the narrow ranges of -2.57 to -2.92 and -2.07 to $-2.32 \mathrm{~V}$ for the pair of BQ and DBQ complexes, respectively. This finding led us to propose that the observed reduction was strongly associated with both BQ and DBQ groups, while the ancillary phosphine ligand has very little influence on the reduction potential.

Photophysical Measurements. The photophysical properties of these $\mathrm{Ru}^{\mathrm{II}}$ complexes can be systematically varied by modifying the cyclometalated ligand chromophores and the ancillary ligands; the respective data are listed in Table 3. It is notable that the lowest absorption of their parent BQ and DBQ complexes 1 and 2 appear at $\lambda_{\max } \sim 395$ and $420 \mathrm{~nm}$, respectively, which are tentatively assigned to the ligandcentered $\pi \pi^{*}$, mixed with small amounts of MLCT transitions. The slightly higher extinction coefficient and occurrence of multiple peak maxima in the higher energy region for the DBQ complex $\mathbf{2}$ are obviously caused by the extended $\pi$ conjugation of the DBQ ligands.

Moreover, the respective $\mathrm{PPh}_{2} \mathrm{Me}$ - and $\mathrm{PPhMe}_{2}$-substituted BQ complexes showed the occurrence of red-shifted, less intense transitions at $\lambda_{\max } 456 \mathrm{~nm}$ for $\mathbf{3}$ and $458 \mathrm{~nm}$ for $\mathbf{4}$, which are tentatively assigned to the transition incorporating a state mixing among singlet and triplet metal-ligand charge transfer ( ${ }^{1}$ MLCT and ${ }^{3}$ MLCT) and, to a certain extent, the intraligand ${ }^{3} \pi \pi$ transitions. The close energetics and absorptivity between ${ }^{1}$ MLCT and ${ }^{3}$ MLCT bands suggest that the ${ }^{3}$ MLCT transition, induced by the spin-orbit coupling and the proximal energy levels with respect to ${ }^{1}$ MLCT, is greatly enhanced and becomes partially allowed. ${ }^{22}$ Following the same principle, the MLCT transitions of both complexes 5 (506 $\mathrm{nm})$ and $\mathbf{6}(513 \mathrm{~nm})$ can be assigned, for which the more electron-rich $\mathrm{PPhMe}_{2}$-substituted 6 has induced a slightly further bathochromic shift compared with

(22) (a) Kavitha, J.; Chang, S.-Y.; Chi, Y.; Yu, J.-K.; Hu, Y.-H.; Chou, P.-T.; Peng, S.-M.; Lee, G.-H.; Tao, Y.-T.; Chien, C.-H.; Carty, A. J. Adv. Funct. Mater. 2005, 15, 223. (b) Chang, S.-Y.; Kavitha, J.; Li, S.-W.; Hsu, C.-S.; Chi, Y.; Yeh, Y.-S.; Chou, P.-T.; Lee, G.-H.; Carty, A. J.; Tao, Y.-T.; Chien, C.-H. Inorg. Chem. 2006, 45, 137.

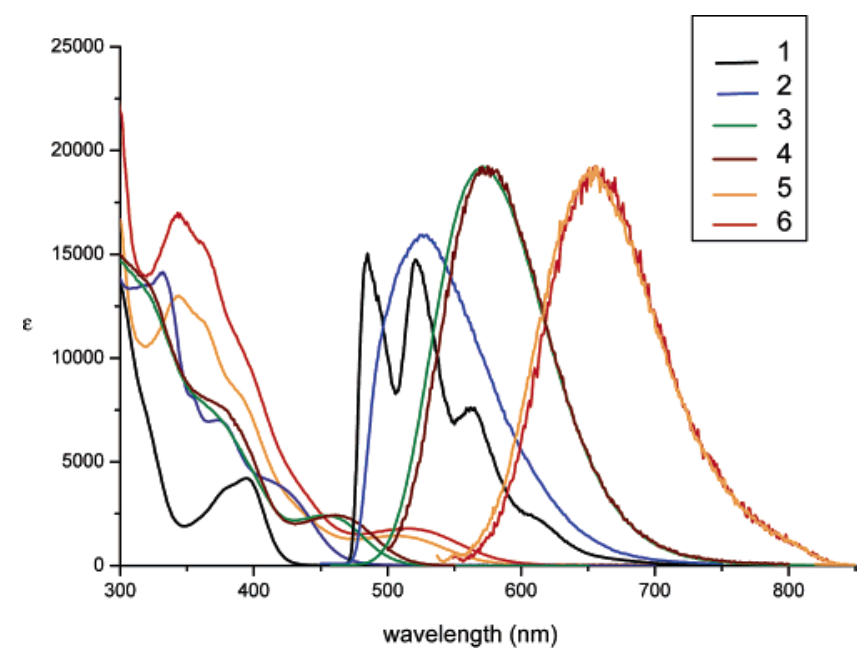

Figure 2. UV-vis absorption and emission spectra of complexes 1-6 in a $\mathrm{CH}_{2} \mathrm{Cl}_{2}$ solution, for which the emissions of $\mathbf{1}$ and $\mathbf{2}$ were taken in a 77 $\mathrm{K}$ matrix, while those of 3-6 were recorded at room temperature.

the slightly electron-deficient $\mathrm{Ru}^{\mathrm{II}}$ metal core in $\mathbf{5}$. Further support for these assignments is given in the Discussion section.

Although they have the largest $\mathrm{S}_{0} \rightarrow \mathrm{S}_{1}$ absorption gap among complexes $\mathbf{1 - 6}$, to our surprise, both $\mathbf{1}(\Phi \sim 0)$ and $2\left(\Phi \leq 5.0 \times 10^{-4}\right)$ are nearly nonemissive in a roomtemperature $\mathrm{CH}_{2} \mathrm{Cl}_{2}$ solution, as well as showing significant temperature-dependent emissive behavior. For example, upon cooling of the solution from 298 to $203 \mathrm{~K}$, the emission yield gradually increased from null to $8 \times 10^{-4}$ for $\mathbf{1}$. The emission possesses a well-resolved vibronic progression with a $0-0$ transition peak at $\sim 485 \mathrm{~nm}$. Both 1 and 2 revealed decent emission signals in the $77 \mathrm{~K}$ solid $\mathrm{CH}_{2} \mathrm{Cl}_{2}$ matrix, and data are depicted in Figure 2 and Table 3.

In sharp contrast to their parent complexes, i.e., $\mathbf{1}$ and $\mathbf{2}$, complexes 3-6 showed strong to weak luminescence in a room-temperature, degassed $\mathrm{CH}_{2} \mathrm{Cl}_{2}$ solution with peak wavelengths located at 571, 575, 655, and $656 \mathrm{~nm}$, respectively (see Figure 2). Owing to the rapid quenching of luminescence in the aerated solution for, e.g., complex $\mathbf{3}$ (not shown here), the assignment of the emission mainly originating from the triplet manifold is unambiguous. Moreover, for complexes 3-6, the partial overlap between the emission

8046 Inorganic Chemistry, Vol. 45, No. 20, 2006 


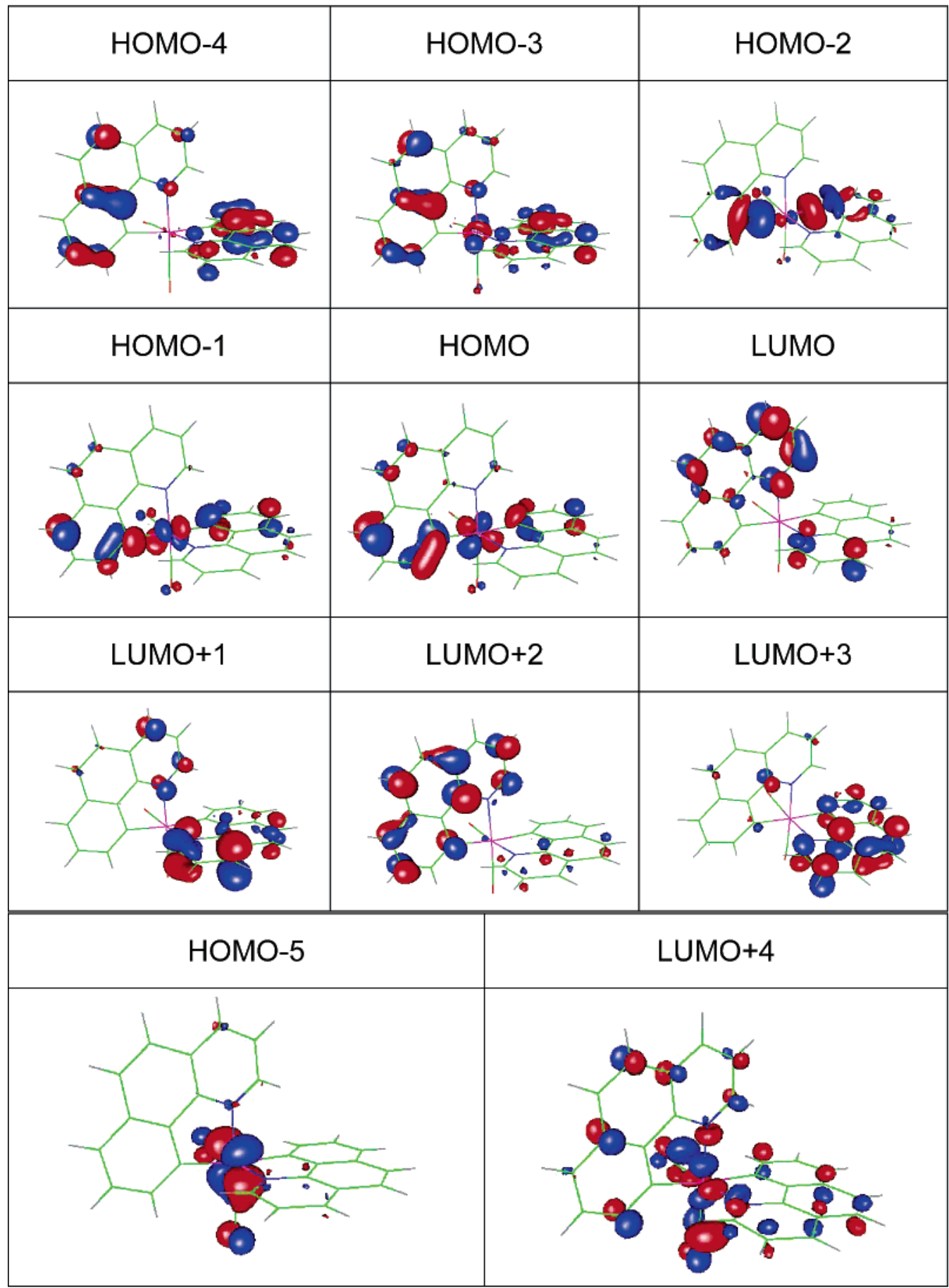

Figure 3. Selected frontier orbitals of $\mathbf{1}$ involved in the lower-lying transitions.

onset and the lowest-energy absorption bands, in combination with a broad, structureless spectral profile, leads us to conclude that the luminescence originates primarily from the ${ }^{3}$ MLCT state. ${ }^{23}$ In comparison to the BQ complex 3, its DBQ counterpart 5 exhibits a $\sim 84$-nm bathochromic shift in $\lambda_{\max }$, the result of which can qualitatively be rationalized by an increase of $\pi$ conjugation and the incorporation of a $\mathrm{C}_{4} \mathrm{~N}_{2}$ hexagon for the DBQ heterocyclic ligands. ${ }^{24}$ In comparison

(23) Vlcek, A., Jr. Coord. Chem. Rev. 1998, 177, 219.

(24) Song, Y.-H.; Yeh, S.-J.; Chen, C.-T.; Chi, Y.; Liu, C.-S.; Yu, J.-K.; Hu, Y.-H.; Chou, P.-T.; Peng, S.-M.; Lee, G.-H. Adv. Funct. Mater. 2004, 14, 1221. to 3 , possessing $\mathrm{PPh}_{2} \mathrm{Me}$, a very slightly bathochromic shift of only $\sim 4 \mathrm{~nm}$ was observed for the $\mathrm{PPhMe}_{2}$-substituted derivative 4. A similar small red shift was resolved between $5\left(\mathrm{PPh}_{2} \mathrm{Me}\right)$ and $6\left(\mathrm{PPhMe}_{2}\right.$; see Table 3$)$. This is apparently caused by the decrease of the $\pi$-accepting strength of $\mathrm{PPhMe}_{2}$ versus the $\mathrm{PPh}_{2} \mathrm{Me}$ ligand. However, the variation seems significantly lower than those expected based on the electronic properties of phosphine ligands. ${ }^{25}$ One possible explanation is that the apparent variation viewed from peak maxima is much reduced because of the broad, structureless spectral profiles. It is also noteworthy that the phosphorescence quantum yields for $5\left(8.0 \times 10^{-3}\right)$ and $\mathbf{6}\left(4.0 \times 10^{-3}\right)$ 
Li et al.

in $\mathrm{CH}_{2} \mathrm{Cl}_{2}$ are significantly lower than those of yellowemitting complexes $3(0.24)$ and 4 (0.18) (see Table 2). For 3-6, the difference could be qualitatively rationalized using an empirical energy gap law. ${ }^{4}$ Upon a decrease in the energy gap, rapid quenching may take place via the $T_{1}-S_{0}$ intersystem crossing through coupling of certain high-frequency vibration motions and subsequent solvent collisional deactivation in the fluid solution. In sharp contrast, although the $\mathrm{T}_{1}-\mathrm{S}_{0}$ energy gap for both $\mathbf{1}$ and $\mathbf{2}$ is larger than that of 3-6, the corresponding phosphorescence is much weaker. Certainly, the results for $\mathbf{1}$ and $\mathbf{2}$ are opposite to the empirical energy gap law and must be associated with other mechanisms of deactivation. Details regarding types of specific modes involved in the radiationless deactivation are elaborated in the Discussion section.

\section{Discussion}

In light of the search for blue phosphorescent materials for fabrication of OLEDs, tuning of the emission color becomes an urgent task, the feasibility of which may be made by systematic variation of the ligand chromophores as well as the ancillary ligands. However, a fundamental question is promptly raised regarding the inferior factors that might induce the rapid radiationless decay processes, giving rise to low quantum efficiency for most of the authentic blue phosphors documented in the literature. ${ }^{8-10}$ Apparently, the room-temperature nonemissive complex 1 (with a 485-nm emission peak at $77 \mathrm{~K}$ ) falls in this category. Following the initial population to the low-lying ${ }^{3} \mathrm{MLCT}$ or ${ }^{3} \pi \pi^{*}$ excited states, one widely accepted radiationless deactivation channel may be ascribed to their rapid crossing to the adjacent or even lower metal-centered ${ }^{3} \mathrm{dd}$ state. Because of its antibonding character, the potential energy surface of the dd state, theoretically, is expected to be shallow, and it may intercept with the potential energy surface associated with the ground state and, in an extreme case, may even undergo bond dissociation. The net results should cause rapid energy dissipation through metal-ligand bond stretching. This, in combination with the forbidden nature of the $S_{0} \rightarrow{ }^{3} d d$ transition, further signifies the importance of the ${ }^{3} \mathrm{dd}$ state in manipulating the radiationless pathways.

To gain detailed insights into this fundamental issue, theoretical approaches (TDDFT, see the Experimental Section) on the photophysical properties were performed for the $\mathrm{Ru}^{\mathrm{II}}$ complexes studied. Figure 3 depicts the features of the selected occupied and unoccupied frontier orbitals mainly involved in the lower-lying transitions for complex $\mathbf{1}$, while the descriptions and energy gaps of each transition are listed in Table 4. As shown in Table 4, the lowest singlet $S_{0} \rightarrow S_{1}$ transition of $391 \mathrm{~nm}$ is in good agreement with the $\pi \pi^{*}$ transition of $395 \mathrm{~nm}$ obtained from its absorption spectra. Likewise, the estimated $\mathrm{S}_{0} \rightarrow \mathrm{T}_{1}$ transition occurring at 471 $\mathrm{nm}$ is consistent with the resolved $485 \mathrm{~nm}$ emission in the $77 \mathrm{~K} \mathrm{CH}_{2} \mathrm{Cl}_{2}$ matrix.

(25) (a) Vogler, A.; Kunkely, H. Coord. Chem. Rev. 2002, 230, 243. (b) Tung, Y.-L.; Wu, P.-C.; Liu, C.-S.; Chi, Y.; Yu, J.-K.; Hu, Y.-H.; Chou, P.-T.; Peng, S.-M.; Lee, G.-H.; Tao, Y.; Carty, A. J.; Shu, C.-F.; Wu, F.-I. Organometallics 2004, 23, 3745. (c) Tsubaki, H.; Tohyama, S.; Koike, K.; Saitoh, H.; Ishitani, O. Dalton Trans. 2005, 385.
Table 4. Calculated Energy Levels of the Lower-Lying Transitions of $\mathbf{1}$

\begin{tabular}{|c|c|c|c|c|}
\hline & assignment & {$[\mathrm{nm}]$} & $E[\mathrm{eV}]$ & $f$ \\
\hline $\mathrm{T}_{1}$ & $\begin{array}{l}\text { HOMO } \rightarrow \text { LUMO }(+33 \%) \\
\text { HOMO-1 } \rightarrow \text { LUMO }(+20 \%) \\
\text { HOMO } \rightarrow \text { LUMO+2 }(+9 \%) \\
\text { HOMO-3 } \rightarrow \text { LUMO }(9 \%) \\
\text { HOMO-1 } \rightarrow \text { LUMO+2 }(+7 \%) \\
\text { HOMO } \rightarrow \text { LUMO+1 }(7 \%) \\
\text { HOMO-4 } \rightarrow \text { LUMO }(6 \%) \\
\text { HOMO-1 } \rightarrow \text { LUMO+1 }(6 \%)\end{array}$ & 471.4 & 2.63 & $\sim 0$ \\
\hline $\mathrm{T}_{2}$ & $\begin{array}{l}\text { HOMO } \rightarrow \text { LUMO+1 }(+15 \%) \\
\text { HOMO- } \rightarrow \text { LUMO }+1(13 \%) \\
\text { HOMO-3 } \rightarrow \text { LUMO+1 }(12 \%) \\
\text { HOMO-1 } \rightarrow \text { LUMO }(10 \%) \\
\text { HOMO-1 } \rightarrow \text { LUMO+3 }(8 \%) \\
\text { HOMO } \rightarrow \text { LUMO }(+7 \%) \\
\text { HOMO-4 } \rightarrow \text { LUMO+1 }(+7 \%) \\
\text { HOMO } \rightarrow \text { LUMO+3 }(+6 \%) \\
\text { HOMO-2 } \rightarrow \text { LUMO+1 }(6 \%)\end{array}$ & 452.8 & 2.74 & $\sim 0$ \\
\hline \multicolumn{5}{|c|}{ Singlet States } \\
\hline$S_{1}$ & $\begin{array}{l}\text { HOMO } \rightarrow \text { LUMO }(+75 \%) \\
\text { HOMO-1 } \rightarrow \text { LUMO }(13 \%) \\
\text { HOMO-2 } \rightarrow \text { LUMO }(+8 \%)\end{array}$ & 391.4 & 3.17 & 0.0083 \\
\hline $\mathrm{S}_{2}$ & $\begin{array}{l}\text { HOMO- } 1 \rightarrow \text { LUMO }(+57 \% \\
\text { HOMO } \rightarrow \text { LUMO } 1(+17 \%) \\
\text { HOMO } \rightarrow \text { LUMO }(+11 \%) \\
\text { HOMO-2 } \rightarrow \text { LUMO }(6 \%)\end{array}$ & 382.0 & 3.25 & 0.0149 \\
\hline
\end{tabular}

Giving another example of the $\mathrm{PPh}_{2} \mathrm{Me}$-substituted complex 3 (see Figure 4 and Table 5), the lowest singlet state $\left(\mathrm{S}_{1}\right)$ with an energy gap of $457 \mathrm{~nm}$ consists of a highest occupied molecular orbital (HOMO) $\rightarrow$ lowest unoccupied molecular orbital (LUMO) transition, while the lowest triplet state $\left(\mathrm{T}_{1}\right)$, with a lower gap of $507 \mathrm{~nm}$, mainly involves $\mathrm{HOMO} \rightarrow \mathrm{LUMO}+1$ transition, for which the electron densities of the HOMO are located on the $\mathrm{C}_{6}$ hexagon of one $\mathrm{BQ}$ ligand trans to the $\mathrm{CO}$ ligand and the central $\mathrm{Ru}$ atom, whereas those of the $\mathrm{LUMO}+1$ are primarily distributed on the same BQ ligand. The calculated lowest excited singlet and triplet states at 457 and $507 \mathrm{~nm}$, respectively, are also qualitatively in agreement with those (the absorption peak maximum at $456 \mathrm{~nm}$ and the phosphorescence onset of $\sim 510 \mathrm{~nm}$ ) observed experimentally. We believe that the small deviation of theoretical prediction from experimental results is mainly due to its limitation in predicting the minute nuclear motion during the electronic transitions as well as the negligence of the solvation energy in the current theoretical approach. Qualitative consistency between theoretical approaches and experimental results is also seen in the rest of the metal complexes, for which the theoretical results of the DBQ complex 5 are revealed in Figure 5 and Table 6. As for a general trend, the $S_{0}-S_{1}$ and $S_{0}-T_{1}$ energy gaps for complexes filled with dual ancillary $\mathrm{CO}$ ligands are much larger than those anchored by one $\mathrm{CO}$ and one phosphine, showing the expected hypsochromic shift imposed by the stronger $\pi$-accepting $\mathrm{CO}$ ligands.

Theoretical results provide valuable clues to the exploration of the correlation between each electronic transition and its corresponding frontier orbital contribution. A similar trend was also resolved for these complexes, in which the $S_{0} \rightarrow$ $\mathrm{T}_{1}$ transition is dominated by either $\mathrm{Ru}^{\mathrm{II}} \rightarrow \mathrm{BQ}$ (for $\mathbf{1}, \mathbf{3}$, and 4 ) or $\mathrm{Ru}^{\mathrm{II}} \rightarrow$ DBQ (for $\mathbf{2}, \mathbf{5}$, and 6) MLCT in combination with $\pi \pi^{*}$ transitions within BQ or DBQ ligands. This 


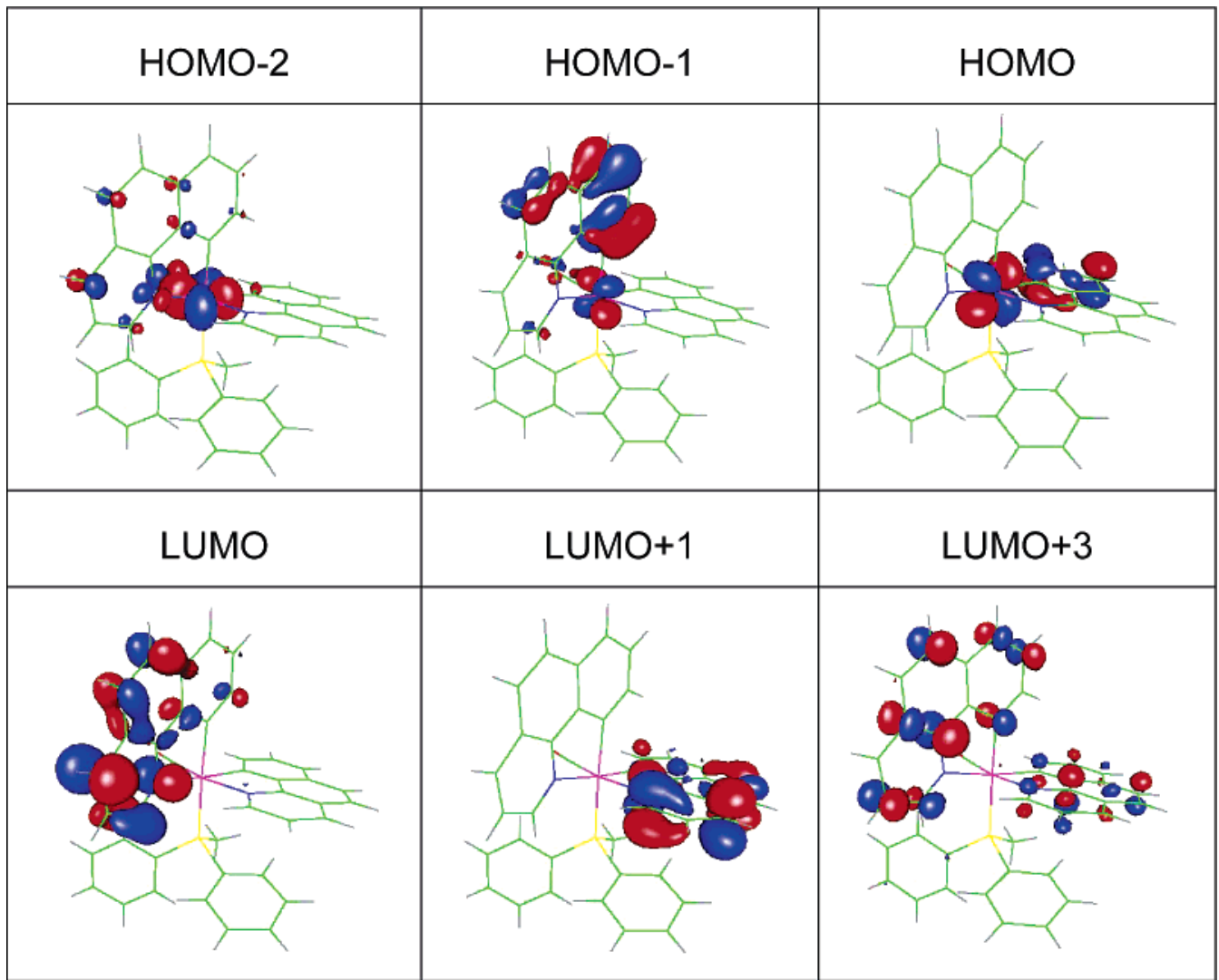

Figure 4. Selected frontier orbitals of $\mathbf{3}$ involved in the lower-lying transitions.

Table 5. Calculated Energy Levels of the Lower-Lying Transitions of 3

\begin{tabular}{ccccc}
\hline \multicolumn{1}{c}{ assignment } & {$[\mathrm{nm}]$} & $E[\mathrm{eV}]$ & $f$ \\
\hline $\mathrm{T}_{1}$ & HOMO $\rightarrow$ LUMO+1 $(+88 \%)$ & 506.9 & 2.45 & $\sim 0$ \\
$\mathrm{~T}_{2}$ & HOMO-1 $\rightarrow$ LUMO $(+66 \%)$ & 483.6 & 2.56 & $\sim 0$ \\
& HOMO-2 $\rightarrow$ LUMO $(+15 \%)$ & & & \\
\multicolumn{5}{c}{ HOMO-4 $\rightarrow$ LUMO $(+8 \%)$} \\
$\quad$ SOMO-1 $\rightarrow$ LUMO+3 $(+7 \%)$ \\
$\quad$ Singlet States \\
$\mathrm{S}_{1} \quad$ HOMO $\rightarrow$ LUMO $(+96 \%)$ & 457.3 & 2.71 & 0.0002 \\
$\mathrm{~S}_{2}$ & HOMO $\rightarrow$ LUMO+1 $(+89 \%)$ & 441.9 & 2.81 & 0.0217
\end{tabular}

characteristic is somewhat similar to those of $\operatorname{Ir}(\mathrm{ppy})_{3}$ and its derivatives, which were also attributed to a ${ }^{3} \pi \pi^{*}$ manifold, which, to a great extent, was mixed with the ${ }^{3}$ MLCT character. ${ }^{26}$ Upon careful examination of the associated frontier orbitals involved in each transition of our complexes, to our surprise, the calculated lowest-lying $\mathrm{T}_{1}$ state and even the $\mathrm{S}_{0} \rightarrow \mathrm{T}_{2}$ or higher energy transitions have no contribution from the metal-centered $\mathrm{d}_{\pi} \mathrm{d}_{\sigma^{*}}$ and/or ligand-to-metal $\pi \mathrm{d}_{\sigma^{*}}$ states. Instead, the unoccupied orbitals with $\mathrm{d}_{\sigma^{*}}$ character are ascribed to LUMO+4 for $\mathbf{1}$ (Figure 3) and even higher for other complexes. For the case of $\mathbf{1}$, the $\mathrm{d}_{\pi} \mathrm{d}_{\sigma^{*}}$ state is higher in energy than the $\mathrm{T}_{1}$ state by $1.5 \mathrm{eV}$. This gap is so large that, even under the excited-state geometry relaxation, a chance of the intersection of the potential energy surface between $\mathrm{d}_{\pi} \mathrm{d}_{\sigma^{*}}$ and $\mathrm{T}_{1}$ states seems to be rather slim and the associated $\mathrm{d}_{\pi} \mathrm{d}_{\sigma^{*}}$ triplet state is strictly thermally inaccessible. These results simply discard a generally accepted mechanism

(26) Hay, P. J. J. Phys. Chem. A 2002, 106, 1634. incorporating the ${ }^{3} \mathrm{~d}_{\pi} \mathrm{d}_{\sigma^{*}}$ (or ${ }^{3} \pi \mathrm{d}_{\sigma^{*}}$ ) state being responsible for the lack of room-temperature emission for dicarbonyl complexes $\mathbf{1}$ and $\mathbf{2}$.

On the other hand, the typical lowest-energy transition in the triplet manifold involves a great extent of $\pi \pi^{*}$ and MLCT mixing. Because MLCT incorporates a $\mathrm{d}_{\pi} \rightarrow \pi^{*}$ transition, its key role in enhancing the spin-orbit coupling is obvious; namely, the more ${ }^{3} \mathrm{MLCT}$ contribution, the greater the spinorbit coupling, and hence the faster radiative rate of the ${ }^{3} \mathrm{MLCT} \rightarrow \mathrm{S}_{0}$ transition. ${ }^{10,27}$ We thus carefully examined the percentage of ${ }^{3} \mathrm{MLCT}$ contribution to the $\mathrm{T}_{1}$ state. As shown in Table 7, it appears to us that the percentages of MLCT contribution in the $\mathrm{T}_{1}$ state of $\mathbf{1}(10.2 \%)$ and $\mathbf{2}(12.4 \%)$ are significantly lower than those of $\mathbf{3}-\mathbf{6}(>40 \%)$. The results can be rationalized by the greater $\pi$-accepting properties of $\mathrm{CO}$ than those of $\mathrm{PPh}_{2} \mathrm{Me}$ and $\mathrm{PPhMe}_{2}$ ligands, such that complexes 1 and $\mathbf{2}$ with dual CO ligands render a much reduced electron density in the $\mathrm{d}_{\pi}$ orbital, giving a lesser amount of the MLCT contribution.

Further support of the above viewpoint is given by two additional observations. First, from the steady-state approach, the observation of vibronic progression of phosphorescence for 1 in $77 \mathrm{~K} \mathrm{CH}_{2} \mathrm{Cl}_{2}$ provides indirect evidence that phosphorescence should contain an excess of $\pi \pi^{*}$ character. Conversely, 3-6 showed a broad, diffusive phosphorescence even at $77 \mathrm{~K}$, strongly indicating their dominance of the ${ }^{3}$ MLCT character. Moreover, as for the time-resolved meas-

(27) Yutaka, T.; Obara, S.; Ogawa, S.; Nozaki, K.; Ikeda, N.; Ohno, T.; Ishii, Y.; Sakai, K.; Haga, M. Inorg. Chem. 2005, 44, 4737. 


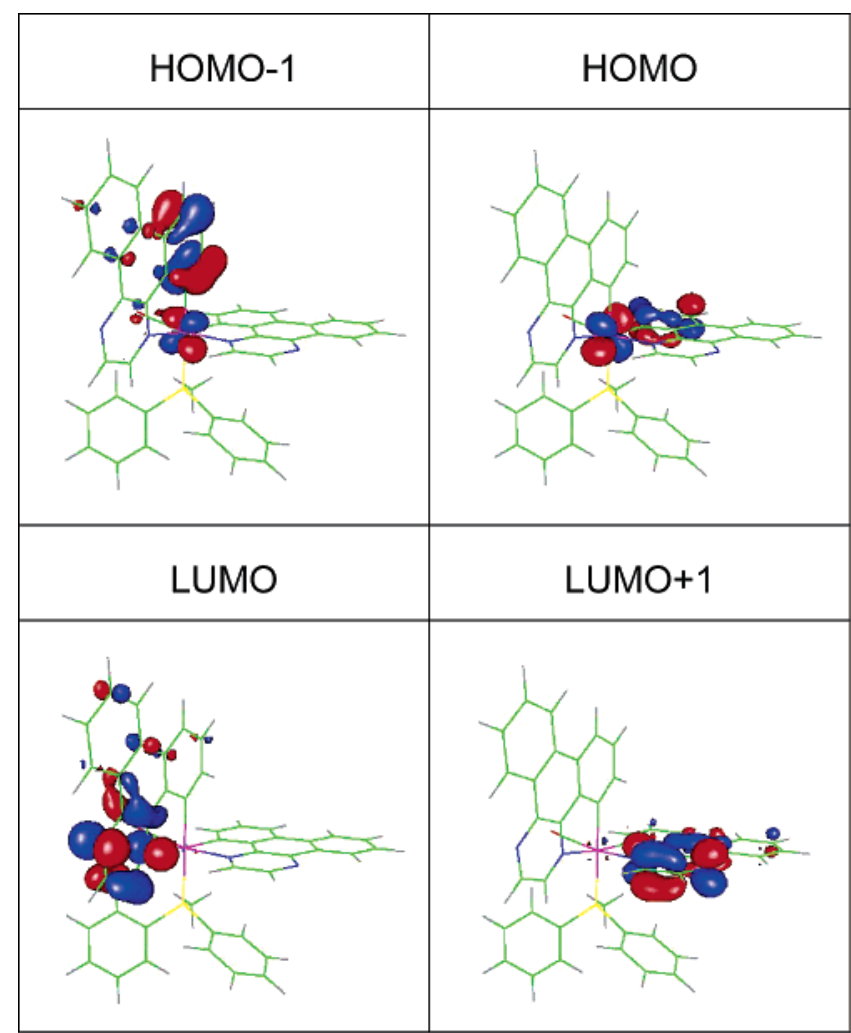

Figure 5. Selected frontier orbitals of $\mathbf{5}$ involved in the lower-lying transitions.

Table 6. Calculated Energy Levels of the Lower-Lying Transitions of 5

\begin{tabular}{ccccc}
\hline & assignment & {$[\mathrm{nm}]$} & $E[\mathrm{eV}]$ & $f$ \\
\hline $\mathrm{T}_{1}$ & HOMO $\rightarrow$ LUMO+1 $(+98 \%)$ & 539.9 & 2.30 & $\sim 0$ \\
$\mathrm{~T}_{2}$ & HOMO $\rightarrow$ LUMO $(+88 \%)$ & 507.6 & 2.44 & $\sim 0$ \\
\multicolumn{5}{c}{ HOMO-1 $\rightarrow$ LUMO (7\%) } \\
$\quad$ Singlet States \\
$\mathrm{S}_{1}$ & HOMO $\rightarrow$ LUMO $(+96 \%)$ & 505.0 & 2.46 & 0.0002 \\
$\mathrm{~S}_{2}$ & HOMO $\rightarrow$ LUMO $+1(+90 \%)$ & 485.4 & 2.55 & 0.0166
\end{tabular}

Table 7. Percentage of the MLCT State Contributing to the Lowest Electronic Transition in Singlet and Triplet Manifolds

\begin{tabular}{lcccccc}
\hline & \multicolumn{6}{c}{ complex } \\
\cline { 2 - 7 } state & $\mathbf{1}$ & $\mathbf{2}$ & $\mathbf{3}$ & $\mathbf{4}$ & $\mathbf{5}$ & $\mathbf{6}$ \\
\hline $\mathrm{S}_{1}$ & 11.0 & 13.1 & 44.1 & 45.4 & 45.3 & 43.9 \\
$\mathrm{~T}_{1}$ & 10.1 & 12.4 & 40.5 & 46.4 & 46.2 & 48.3
\end{tabular}

urement, although the radiative decay time of $\mathbf{1}$ could not be deduced because of the nearly nonemissive properties at ambient temperature, the decay time of $2400 \mu$ s measured at $77 \mathrm{~K}$ is far longer than the $30-50 \mu$ s deduced for complexes 3-6. A rather similar long radiative decay time of $540 \mu \mathrm{s}$ was also deduced for complex $\mathbf{2}$. For $\mathbf{1}$ and $\mathbf{2}$, according to the exceedingly longer radiative decay time, its dominant ${ }^{3} \pi \pi$ character in the $T_{1}$ state is obvious, consistent with the theoretical approach. The emission quantum yield $\Phi$ is defined as $\Phi=k_{\mathrm{r}} / k_{\mathrm{obs}}=k_{\mathrm{r}} /\left(k_{\mathrm{r}}+k_{\mathrm{nr}}\right)$, in which subscripts $\mathrm{r}, \mathrm{nr}$, and obs denote radiative, nonradiative, and observed decay components, respectively. Thus, for complexes possessing a small $k_{\mathrm{r}}$ value, such as $\mathbf{1}$ and $\mathbf{2}$, the $k_{\mathrm{nr}}$ value should quite effectively influence the emission quantum yield and hence the emission intensity. Experimentally, this is apparently true and can qualitatively explain the nonemissive (weak-emissive) property for $\mathbf{1}$ and $\mathbf{2}$.

Nevertheless, from the quantitative viewpoint, the deduced radiationless decay rates of $\mathbf{1}$ [ $\geq 4.2 \times 10^{6} \mathrm{~s}^{-1}$, assuming a detection limit of $\Phi \sim 10^{-4}$ in our current system and 2400 $\mu$ s $($ at $77 \mathrm{~K})$ for the radiative decay time] and $2(\sim 3.7 \times$ $\left.10^{6} \mathrm{~s}^{-1}\right)$ are larger than those deduced from $3\left(1.04 \times 10^{5}\right.$ $\left.\mathrm{s}^{-1}\right)$ and $4\left(9.6 \times 10^{4} \mathrm{~s}^{-1}\right)$, which possess the same BQ and DBQ ligands. For rationalization, our first attempt is the weakening of the $\mathrm{Ru}-\mathrm{CO}$ bonds upon excitation if the net result of MLCT is to induce an electron transfer to the BQ or DBQ chelates trans to the CO ligands. However, thorough frontier orbital analysis clearly indicates that the $\mathrm{Ru}-\mathrm{CO}$ back- $\pi$-bonding character is present only in the very stable occupied molecular orbital of HOMO-5 (Figure 3) and even lower ones (not shown here). Thus, it is very unlikely that the strength of such a strong $\mathrm{Ru}-\mathrm{CO}$ bond, upon excitation, could be drastically weakened; consequently, the associated $\mathrm{Ru}-\mathrm{CO}$ stretching modes should not act as a main radiationless deactivation pathway. In fact, strong to moderate emission has been reported in numerous carbonyl-containing third-row transition-metal complexes, in which MLCT transition occurs at the ligand chromophore trans to the ancillary $\mathrm{CO}$ ligands. ${ }^{28}$

Alternatively, in our opinion, it is more plausible to correlate the rapid radiationless deactivation in $\mathbf{1}$ and $\mathbf{2}$ with respect to the increase of the vibrational modes channeling into the radiationless deactivation pathways. As depicted in Tables $4-6$, it is obvious that, despite a very simple contribution, i.e., $\mathrm{HOMO} \rightarrow \mathrm{LUMO}+1$, to the $\mathrm{T}_{1}$ state in $\mathbf{3}$ and $\mathbf{5}$, a much more complicated frontier orbital contribution was observed in 1, incorporating HOMO to HOMO-4 and LUMO to LUMO+2 (see Table 4). Careful analyses indicated that the associated frontier orbitals spread out to both $\mathrm{BQ}$ ligands simultaneously rather than to only one $\mathrm{BQ}$ site trans to the unique $\mathrm{CO}$ ligand for $\mathbf{3}$ and $\mathbf{4}$. Multiple contributions were observed for $\mathrm{T}_{1}$ in complex 2 (see the Supporting Information). The results can be tentatively rationalized by the two BQ and DBQ chelate ligands being subjected to identical coordinating environments in both $\mathbf{1}$ and $\mathbf{2}$. In contrast, a simplified $\mathrm{T}_{1}$ state was also noted in $\mathbf{5}$ and $\mathbf{6}$. The radiationless decay rates were deduced to be $4.12 \times 10^{6}$ and $7.12 \times 10^{6} \mathrm{~s}^{-1}$, both more than 1 order of magnitude larger than those of $\mathbf{3}$ and $\mathbf{4}$, and can be rationalized by the greater degree of vibrational freedom in combination with radiationless transition governed by the empirical energy gap law. ${ }^{4}$ Accordingly, despite the same order of magnitude in radiative decay time with respect to 3 and $\mathbf{4}$, greatly inferior phosphorescence quantum yields were observed for $\mathbf{5}$ and $\mathbf{6}$.

As for the thermal activation on the nonradiative deactivation, we have performed a temperature-dependent study on

(28) (a) Van Slageren, J.; Stufkens, D. J. Inorg. Chem. 2001, 40, 277. (b) Yam, V. W.-W. Chem. Commun. 2001, 789. (c) Cheng, Y.-M.; Yeh, Y.-S.; Ho, M.-L.; Chou, P.-T.; Chen, P.-S.; Chi, Y. Inorg. Chem. 2005, 44, 4594. (d) Chen, Y.-L.; Lee, S.-W.; Chi, Y.; Hwang, K.-C.; Kumar, S. B.; Hu, Y.-H.; Cheng, Y.-M.; Chou, P.-T.; Peng, S.-M.; Lee, G.H.; Yeh, S.-J.; Chen, C.-T. Inorg. Chem. 2005, 44, 4287. 


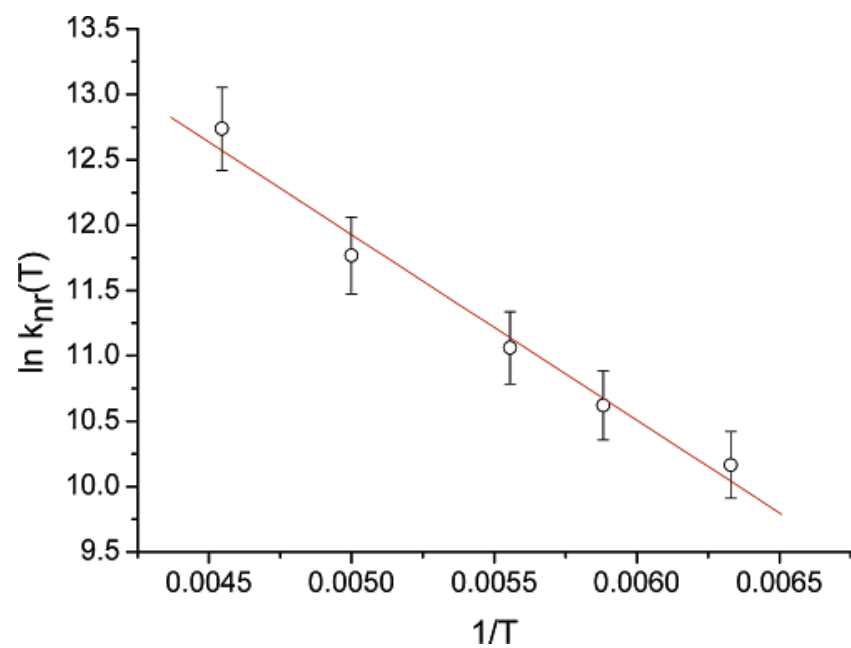

Figure 6. Plot of the logarithm of $k_{\mathrm{nr}}(T)$ vs $1 / T$ in the range of 220-150 $\mathrm{K}$ (see the text for the definition of $k_{\mathrm{nr}}$ ).

complex 1. Because of its lack of emission at ambient temperature, the experiment was performed in a temperature range of $220-150 \mathrm{~K}$. As a result, the plot of the logarithm of $k_{\mathrm{nr}}(T)$ vs $1 / T$, in which $k_{\mathrm{nr}}(T) \sim k_{\mathrm{obs}}-k_{\mathrm{r}}$, rendered a sufficiently straight line (see Figure 6). As a result, a $\Delta E_{\mathrm{a}}$ value of $2.78 \mathrm{kcal} \mathrm{mol}^{-1}$ and a preexponential factor of $1.7 \times 10^{8} \mathrm{~s}^{-1}$ were deduced. The results indicate that the nonradiative decay rate is dominated by rather low frequency motions, possibly involving the geometry distortion motions coupled with the $\mathrm{T}_{1}-\mathrm{S}_{0}$ intersystem crossing. Although specific modes inducing radiationless transition, at this stage, are pending resolution, the overlap of multiple frontier orbitals in the case of $\mathbf{1}$ (vide supra) should statistically increase the number of active vibrational modes involved in the radiationless deactivation.

\section{Conclusion}

In conclusion, a series of new $\mathrm{Ru}^{\mathrm{II}}$ complexes bearing cyclometalated BQ and DBQ ligands have been designed and synthesized with an aim to investigate the associated photoluminescence properties. Our results solidify the correlation between MLCT and radiative lifetime and hence the efficiency of radiationless deactivation. Complexes $\mathbf{1}$ and $\mathbf{2}$, possessing much less ${ }^{3} \mathrm{MLCT}$ contribution because of the electron deficiency in the $d_{\pi}$ orbital, render a great extent of the ${ }^{3} \pi \pi^{*}$ character for $\mathrm{T}_{1}$ with an exceedingly long radiative lifetime. This, in combination with perhaps the increase of the deactivating modes, gives rise to an essentially nonemissive (very weak emission) property. Under the premise of this proposed mechanism, one may be able to analyze the lower lying electronic transitions and the corresponding frontier orbital analyses, providing a guideline to predict not only the phosphorescence properties such as peak wavelength and transition properties but also the quantum efficiency in a qualitative manner. We thus believe that the results presented here may turn out to be of great importance in the design of luminescent materials incorporating both secondand third-row transition-metal elements.

Acknowledgment. The authors are grateful for financial support from the National Center for High-Performance Computing, The Ministry of Economy, and the National Science Council of Taiwan. We also thank Prof. Ching-Fong Shu for helpful advice on the CV measurements.

Supporting Information Available: X-ray crystallographic data file (CIF) of complex 3 and the calculated energy levels and associated frontier orbitals of the DFT calculation on complexes 1-6. This material is available free of charge via the Internet at http://pubs.acs.org.

IC060066G 